Research Paper

\title{
$A_{2 A} R$ Antagonism with DZD2269 Augments Antitumor Efficacy of Irradiation in Murine Model
}

\author{
Jiaqi Huang ${ }^{1,2}$, Di Zhang ${ }^{1,2}$, Yu Bai ${ }^{3}$, Pamela Yang 3 , Ligang Xing ${ }^{1,2}$, Jinming $\mathrm{Yu}^{1,2}$ \\ 1. Department of Clinical Medicine, Shandong University, Jinan, Shandong 250000, P.R. China. \\ 2. Department of Radiation Oncology, Shandong Cancer Hospital and Institute, Shandong First Medical University and Shandong Academy of Medical \\ Sciences, Jinan, Shandong 250117, P.R. China. \\ 3. Dizal (Jiangsu) Pharmaceutical Co., Ltd., Wuxi, Jiangsu 214028, P.R. China.
}

$\triangle$ Corresponding authors: Dr Ligang Xing, Department of Radiation Oncology, Shandong Cancer Hospital and Institute, Shandong First Medical University and Shandong Academy of Medical Sciences, 440 Jiyan Road, Jinan, Shandong 250117, P.R. China, E-mail: xinglg@medmail.com.cn. Or Dr Jinming Yu, Department of Radiation Oncology, Shandong Cancer Hospital and Institute, Shandong First Medical University and Shandong Academy of Medical Sciences, 440 Jiyan Road, Jinan, Shandong 250117, P.R. China. E-mail: sdyujinming@163.com.

(c) The author(s). This is an open access article distributed under the terms of the Creative Commons Attribution License (https://creativecommons.org/licenses/by/4.0/). See http://ivyspring.com/terms for full terms and conditions.

Received: 2020.01.14; Accepted: 2020.02.27; Published: 2020.03.26

\begin{abstract}
Accumulated extracellular adenosine suppresses antitumor immunity via adenosine $2 A$ receptor $\left(A_{2 A} R\right)$. Blockade of $A_{2 A} R$ with DZD2269 can inhibit phosphorylation of cAMP response element-binding protein mediated by adenosine analogue in vitro and in vivo. Irradiation can cause the release of adenosine and lead to a rapid increase in free extracellular adenosine in the tumour area. DZD2269, a novel $A_{2 A} R$ Antagonism, induces incomplete antitumor responses in multiple syngeneic mouse tumour models. Combining DZD2269 with IR can induce a synergistic anticancer effect. IR increases the infiltration of various subtypes of $\mathrm{T}$ cells, including CD4+, CD8+ and Foxp3+ T cells, into the tumour area. Combining IR and DZD2269 improves the tumour immune microenvironment, leading to suppressed infiltration of regulatory $\mathrm{T}$ (Treg) cells and enhanced IFN- $\mathrm{Y}$ expression by tumour-infiltrating lymphocytes. The results support the use of $A_{2 A} R$ antagonism with DZD2269 as a therapeutic strategy for monotherapy or combination therapy with IR.
\end{abstract}

Key words: adenosine, $\mathrm{A}_{2 \mathrm{~A}} \mathrm{R}$, irradiation, immunotherapy

\section{Introduction}

Immunosuppression plays a key role in cancer progression and metastasis. Recently, immunotherapy has produced dramatic antitumor efficacy in a subset of patients. However, only a fraction of patients benefit from immunotherapy, due to some factors within the tumor microenvironment (TME) that mitigate immune cell infiltration and suppress antitumor immune responses [1]. A group of surface receptors on $\mathrm{T}$ cells, called immune checkpoint proteins, deliver negative signals to $\mathrm{T}$ cells upon engagement of the corresponding ligand expressed on antigen-presenting cells [2]. Tumor cells can exploit the inhibitory mechanism by expressing the immunosuppressive ligands, and preventing the binding of immune checkpoint molecules, such as PD-1 and CTLA-4, by monoclonal antibodies has been found to overcome immunosuppression in cancer therapy[3,4].
Increasing evidence suggests that accumulated extracellular adenosine in the TME can promote tumour growth, suppress antitumor immunity and limit the efficacy of antitumor therapy $[5,6]$. The generation of adenosine was correlated with the resistance to chemotherapy and poor survival in triple-negative breast cancer patients [7]. Furthermore, increased extracellular adenosine levels can protect tumour cells from irradiation (IR)-induced damage and impair the antitumor response [8]. The adenosine $2 \mathrm{~A}$ receptor $\left(\mathrm{A}_{2 \mathrm{~A}} \mathrm{R}\right)$ pathway is the main pathway through which adenosine produces immunosuppressive effect $[9,10]$. Stimulation of $A_{2 A} R$ induces the phosphorylation of cAMP response element-binding protein (CREB) [11]. The inhibition of phosphorylated CREB (pCREB) production induced by stimulation with the high-affinity, stable 
adenosine analogue NECA is frequently used as a readout for the activity of $\mathrm{A}_{2 \mathrm{~A}} \mathrm{R}$ antagonists [12]. In preclinical models $A_{2 A} R$ antagonism showed antitumor effects $[13,14]$. Therefore, combining $A_{2 A} R$ antagonism with IR may enhance the curative effect of radiotherapy.

In this study we reported cooperative antitumor response and explored underlying mechanism of the combination of a novel $\mathrm{A}_{2 \mathrm{~A}} \mathrm{R}$ antagonist DZD2269 and IR in murine cancer model. Our results provided support for combination treatment with $\mathrm{A}_{2 \mathrm{~A}} \mathrm{R}$ antagonism and radiotherapy as promising therapeutic strategy in future clinical trials.

\section{Materials and Methods}

\section{Cell lines and reagents}

Mouse colon cancer cell line MC38 was obtained from the National Cancer Institutes of Health (NIH). Mouse triple negative breast cancer cell line 4T1 was purchased from the American Type Culture Collection (ATCC). MC38 cells were cultured in DMEM (Gibco, Cat. No. 12430-054) + 10\% fetal bovine serum (FBS, Gibco, Cat. No. 10091-148) + 1\% MEM NEAA (Gibco, Cat. No. 11140-050) + 1\% sodium pyruvate (Gibco, Cat. No. 11360-070). 4T1 cells were cultured in RPMI medium 1640 (Gibco, Cat. No. $22400-089)+10 \%$ FBS (Gibco, Cat. No. 10091-148). For adenosine detection in vitro, $10 \mu \mathrm{M}$ hydrochloride (EHNA; Sigma, Cat. No. 58337-38-5), $10 \mu \mathrm{M}$ 5-Iodotubericidin (5-ITU; Sigma, Cat. No. 24386-93-4) and $0.5 \mu \mathrm{M}$ dipyridamole (Sigma, Cat. No. 58-32-2) were added into medium.

DZD2269 was provided by Dizal Pharma (Wuxi, China) and was dissolved in dimethyl sulfoxide for in vitro study. For in vivo study, DZD2269 was prepared with a final concentration of $0.3 \mathrm{mg} / \mathrm{mL}$ in $0.5 \%$ hydroxy propyl methyl cellulose (HPMC; Sigma, Cat. No. 9004-67-5) and 0.1\% Tween-80 (Sigma, Cat. No P1754).

\section{Mouse model}

Six- to eight-week-old C57BL/ 6 and Balb/c mice were purchased from Charles River. Mice were fed in the animal facility at Dizal Pharma for one week prior to tumor engraftment. All animal experiments were approved by the Institutional Animal Care and Use Committee (IACUC) of Dizal Pharma. Tumour cells were suspended in cold serum-free medium at a density of $1 \times 10^{7} / \mathrm{mL}$, and $100 \mu \mathrm{L}$ cell suspension was subcutaneously injected onto the dextral lower-back region of each mouse. Tumour diameter was measured with digital callipers every 2-3 days. Mice were euthanatized when the tumour volume reached $1,500 \mathrm{~mm}^{3}$ or with weight loss $\geq 20 \%$.

\section{Microdialysis}

Microdialysis probes were surgically implanted into an established tumour bulk whose largest diameter had reached $10 \mathrm{~mm}$. Microdialysis was performed with a flow rate of $2 \mu \mathrm{L} /$ minute. PBS supplemented with $0.2 \mu \mathrm{M} \mathrm{CaCl}_{2}$ and $0.1 \mu \mathrm{M} \mathrm{MgCl}_{2}$ was used as perfusion fluid; $10 \mu \mathrm{M}$ EHNA and $10 \mu \mathrm{M}$ 5-ITU were added to the perfusion fluid within $2 \mathrm{~h}$ before use. Concentrations of adenosine were determined by high-performance liquid chromatography (HPLC) with quadrupole mass spectrometry detection using an ACQ Triple Quad 5500 instrument (Acquity UPLC, USA). An amide $1.7 \mu \mathrm{m}$ column (Acquity UPLC, USA) was used for detection. Data were calibrated and quantified with Analyst system (Acquity $^{\mathrm{TM}}$, version 1.6.1).

\section{Measurement of CREB phosphorylation}

Cell lysates were collected after the cells were lysed in lysis buffer (BD, Cat. No. 558049). The lysates were stained with antibody cocktail containing anti-CD8a FITC (BD, Cat. No. 553031), anti-CD45 PE (BD, Cat. No. 553081), and anti-pCREB AF647 (CST, Cat. No. 14001) for $1 \mathrm{~h}$ at room temperature in the dark. Cells were then washed twice with FACS buffer and analyzed on a flow cytometer (Cell Analyzer FACS canto). The mean fluoresce intensity (MFI) of CREB phosphorylation signal was measured.

\section{Immunohistochemistry (IHC)}

Tumor tissues were collected 17 days after tumor engraftment. IHC was performed on $3 \mu \mathrm{m}$ FFPE sections using a Lab Vision autostainer (Thermo). Then, the slides were subjected to antigen retrieval for 15 min followed by incubation with endogenous peroxidase block for $10 \mathrm{~min}$. The sections were incubated with primary antibodies for CD4 (CST, Cat. No. ab183685), CD8 (CST, Cat. No. CST98941) and Foxp3 (CST, Cat. No. CST12653) for $1 \mathrm{~h}$ at room temperature, then with Envision+ System HRPLabelled Polymer Anti-Rabbit (DAKO, Cat. No. K4003) for $30 \mathrm{~min}$ and developed in diaminobenzidine substrate for $5 \mathrm{~min}$. Then, the sections were counterstained, dehydrated and cleared in the Leica $\mathrm{XL}$ autostainer. Positive cell percentage of stained IHC slides was quantified with a HALO ${ }^{\text {TM }}$ system.

\section{In situ hybridization (ISH)}

Tumor tissues were processed as described for IHC, and then incubated with $\mathrm{H}_{2} \mathrm{O}_{2}$ and Protease Plus reagents (ACDbio, Cat. No. 322330; DAKO, Cat. No. $\mathrm{K} 3468$ ), and placed in $40^{\circ} \mathrm{C}$ preheated hybridization buffer (ACDbio, Cat. No. 310013) for $30 \mathrm{~min}$. The samples were washed and incubated with $2.5 \mathrm{HD}$ Detection Kit-BROWN (ACDbio, Cat. No. 322310), the 
slides were then incubated with DAB for 5 min and counterstained. The foci number per stained slides was quantified with a HALO ${ }^{\mathrm{TM}}$ system.

\section{Statistical analysis}

Data were shown as the mean \pm SEM. Two-way ANOVA was applied for comparison of different treatment groups. A $p$ value of $<0.05$ was considered statistically significant.

\section{Results}

\section{DZD2269 blocked $A_{2 A} R$ activation on $T$ cells in vitro and in vivo}

To determine whether DZD2269 relieves the immunosuppressive effects of adenosine on T cells, we detected pCREB levels in T cells. In in vitro assay, DZD2269 inhibited CREB phosphorylation stimulated by $1 \mu \mathrm{M}$ NECA in CD8+ T cells, with an $\mathrm{IC}_{50}$ of approximately $3 \mathrm{nM}$ (Figure 1A). Similar results were observed in $\mathrm{CD}^{+} \mathrm{T}$ cells (Figure 1B, and Supplemental figure S1). In in vivo assay, mice were orally administered with DZD2269 (3 or $10 \mathrm{mg} / \mathrm{kg}$, twice a day) for 3 days before peripheral blood was collected. Pre-treatment with DZD2269 blocked CREB phosphorylation (Figure 1C).
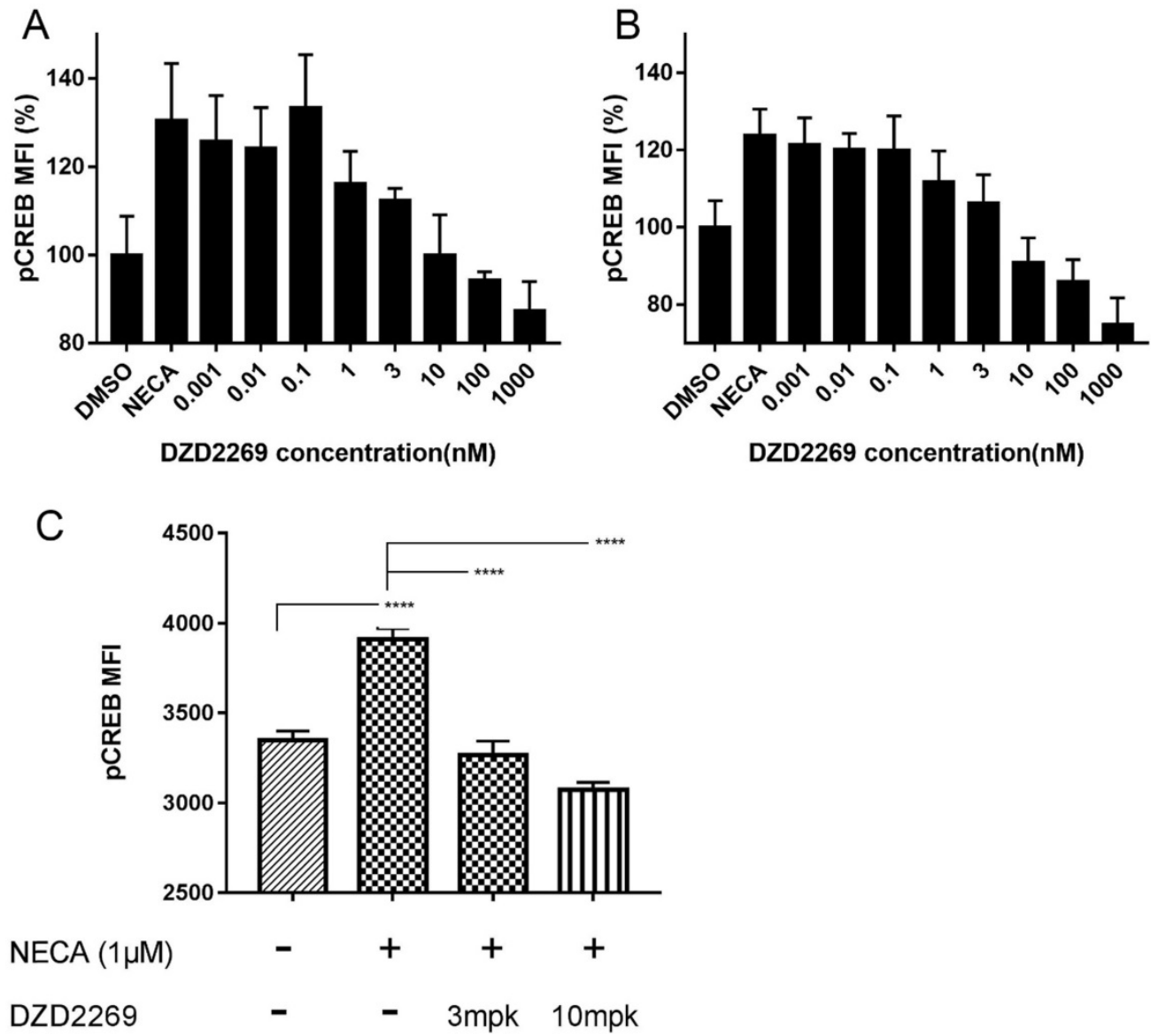

Figure 1. Blockage of A2AR with DZD2269 inhibited CREB phosphorylation in T cells. Mean fluorescence intensity (MFI) of CREB phosphorylation signal compared to DMSO control was measured in mouse (A) CD8+ and (B) CD4+ T cells stimulated by NECA ( $1 \mu M)$ in vitro. (C) MFI of $p C R E B$ in tumor samples of mice ( $n=5$ in each group). 

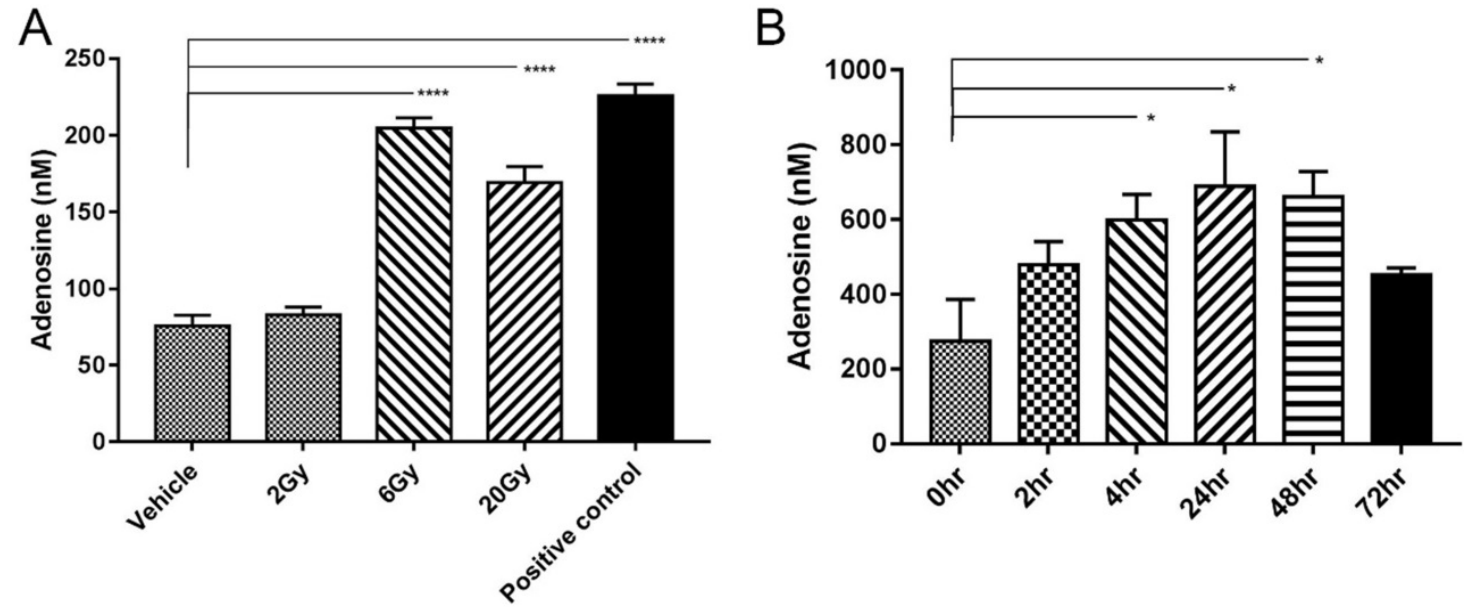

Figure 2. IR induced adenosine release. (A) Adenosine concentration in medium $(\mathrm{n}=3$ ). Samples were collected $24 \mathrm{~h}$ after irradiation. (B) Free extracellular adenosine concentrations at different time points after a single 5 -Gy dose of radiation ( $\mathrm{n}=4$ mice in each group). Error bars represent standard error of the mean. Significance was calculated using One-way ANOVA t-test. $* p<0.05, * * p<0.01, * * * p<0.001$

A

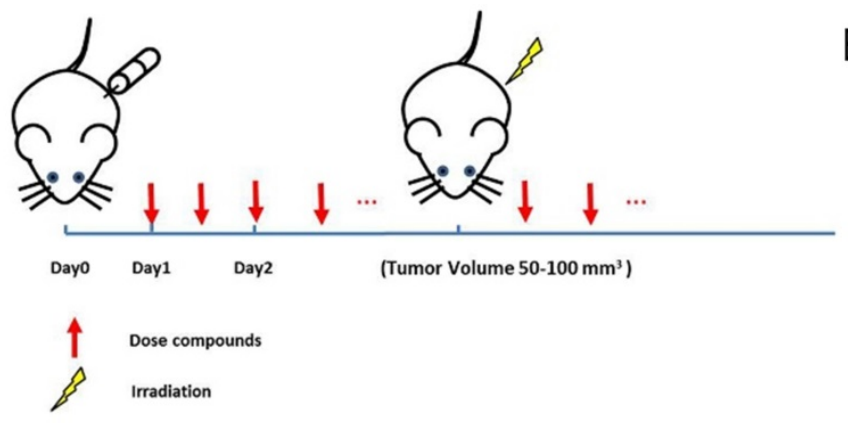

C

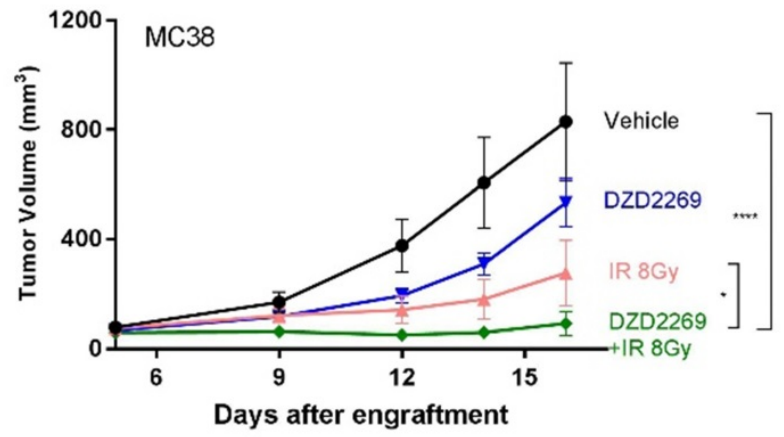

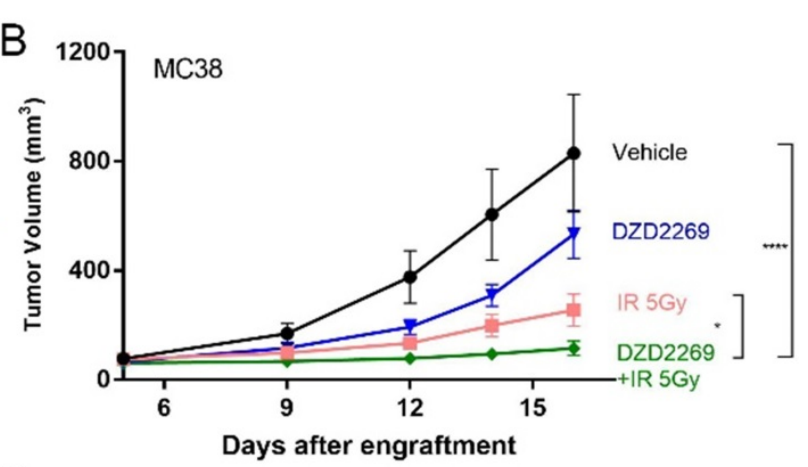

D

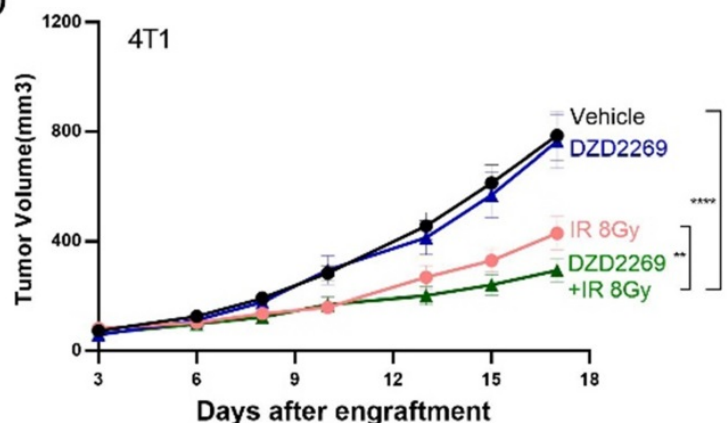

Figure 3. DZD2269 enhanced IR-induced antitumor response. (A) Procedure of tumour engraftment and treatment ( $\mathrm{n}=7)$. (B-C) $D Z D 2269$ (3 mg/kg) or irradiation monotherapy resulted in incomplete antitumor response in MC38 tumour model $(n=9)$. Combined administration of DZD2269 and irradiation with a single dose of 5 Gy $(B)$ or $8 \mathrm{~Gy}$ (C) significantly inhibited tumour growth. (D) Similar results were observed in 4T1 tumour model with an irradiation dose of $8 \mathrm{~Gy}$. Significance was calculated using two-way ANOVA. $* p<0.05, * * p<0.01, * * * p<0.001, * * * * p<0.0001$.

\section{DZD2269 enhanced IR-induced antitumor response}

Enriched adenosine can mitigate the immune effect of radiotherapy and induce radiation resistance [17]. A2AR inhibitor may counteract the immunosuppressive effects of adenosine and enhance the antitumor efficacy of radiation. Therefore, MC38 or $4 \mathrm{~T} 1$ tumor cells were subcutaneously injected into the back of syngeneic C57BL/6 or Balb/c mice, respectively. The mice were orally administered with DZD2269 (3 mg/ $\mathrm{kg})$ or vehicle control twice a day 24 $\mathrm{h}$ after engraftment. IR was given to the local tumor area 4-5 days after engraftment when the average tumour volume was $50-100 \mathrm{~mm}^{3}$ (Figure 3A). DZD2269 treatment led to incomplete inhibition of tumour volume of approximately 35\% in MC38 model (Figure 3B, C), but not in 4T1 model (Figure 3D). Both MC38 and 4T1 models were sensitive to IR, with suppression ratios of $45.2 \%-69.2 \%$. Compared to either monotherapy, combined treatment with IR and DZD2269 led to synergistic repression of tumor growth (Supplemental figure S2). All treated mice did not display any signs of distress or significant weight loss. 

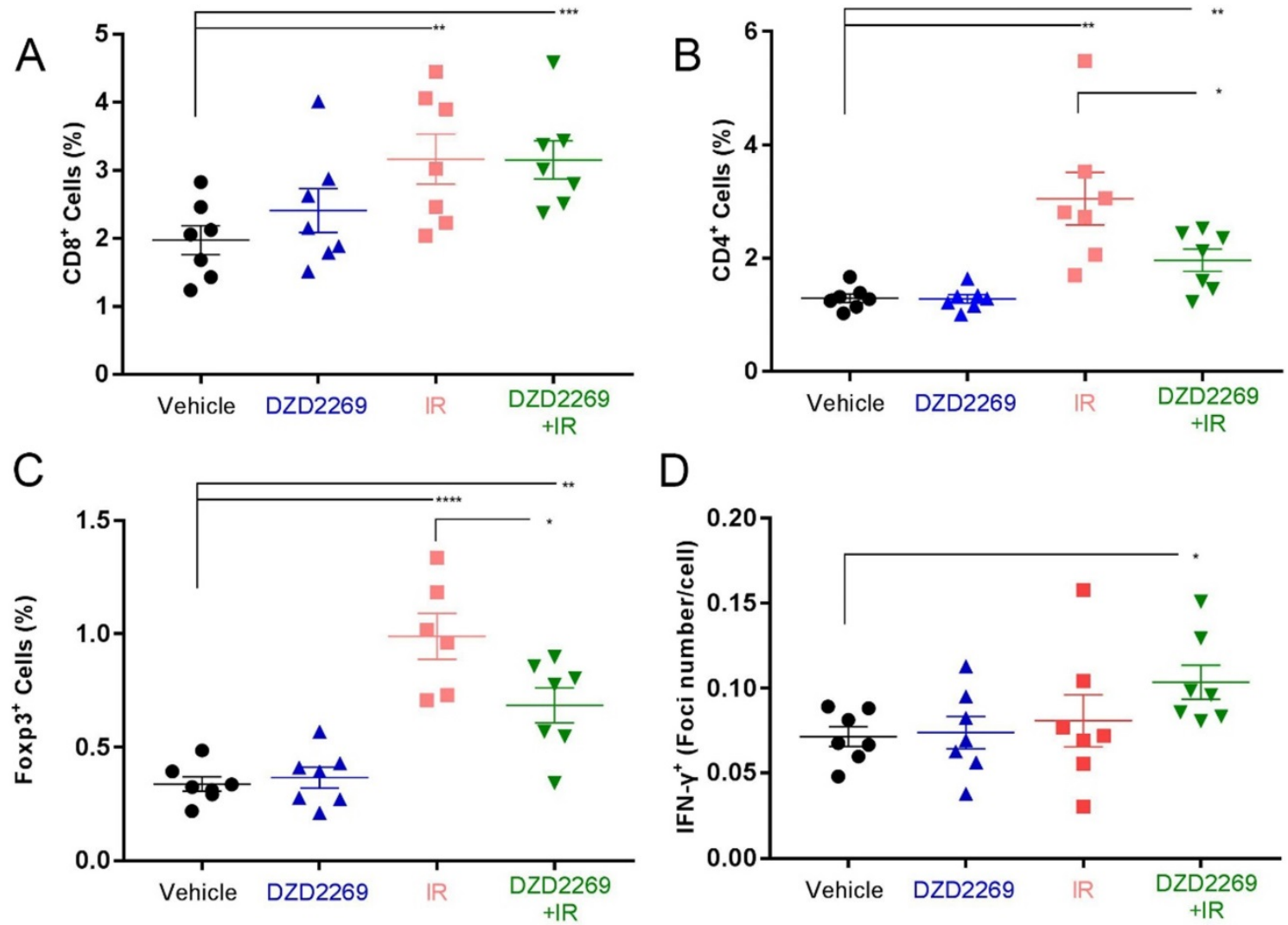

Figure 4. T cell infiltration and IFN-y expression in tumor samples. (A) CD8+ T cell infiltration into MC38 tumors increased following treatment with irradiation, but no further enhancement occurred after combination with DZD2269. (B-C) Irradiation induced increased infiltration of CD4+ (B) and Foxp3+ (C) T cells, which could be mitigated by DZD2269. (D) IFN-Y expression was increased by DZD2269 in combination with irradiation. Significance was calculated using one-way ANOVA t-test ( $\mathrm{n}=7$ ). $* p<0.05, * * p<0.01, * * * p<0.001$.

\section{DZD2269 enhanced T cell infiltration after IR}

IR is known to remodel tumor immune microenvironment, such as the upregulation of MHC-I expression and the recruitment of effector $\mathrm{T}$ cells $[18,19]$. To examine the changes in tumor immune microenvironment, MC38 tumor cells were engrafted into female syngeneic C57BL/ 6 mice, which were then treated with DZD2269 or/and radiation. Tumor-infiltrating lymphocytes expressing CD8, CD4 and Forkhead box 3 (Foxp3) were detected by IHC.

While IR increased the accumulation of CD8+ lymphocytes, no further enhancement was observed after combination with DZD2269 (Figure 4A). The infiltration of CD4+ lymphocytes increased after IR, but combination treatment with DZD2269 suppressed IR-induced recruitment of CD4+ (Figure 4B). Similarly, combination treatment with DZD2269 suppressed IR-induced recruitment of Treg cells (Figure 4C) (Supplemental figure S3-5).

\section{IR combined with DZD2269 enhanced IFN-Y expression in tumour microenvironment}

Cytokines such as IFN- $\gamma$ can predict the response to immune checkpoint inhibitors [20]. $\mathrm{T}$ cell function-related gene expression was reported to be associated with the therapeutic efficacy of $A_{2 A} R$ blockade [16]. To evaluate the correlation between therapy efficacy and $\mathrm{T}$ cell function, IFN- $\gamma$ mRNA expression in tumor tissues was measured by ISH. IR combined with DZD2269 significantly enhanced the mRNA expression of IFN-ץ (Figure 4D) (Supplemental figure S6).

\section{Discussion}

Reprogramming of energy metabolism and evading immune destruction are two emerging hallmarks of cancer, providing new insights for cancer therapy [21]. With the recent discovery of specific mutations in metabolic enzymes in certain cancer types, metabolic pathway are increasingly considered as source of new targets [22]. Meanwhile, treatment of cancer has been revolutionized by immunotherapy with currently widely used checkpoint inhibitors against regulatory immune checkpoint molecules. Adenosine and its receptors are novel targets of checkpoint inhibitors for cancer immunotherapy. Extracellular adenosine is mainly formed by the hydrolysis of tumor cell-derived ATP through the membrane-associated 'tandem ecto-enzymes' CD39/CD73. Adenosine generation in the tumour bulk is mediated by hypoxia-dependent activation of hypoxia-inducible factor 1a. Hypoxia is common in 
solid tumors and is caused by increased $\mathrm{O} 2$ consumption and delayed angiogenesis. Hypoxia causes immunosuppression, promoting tumor recurrence and leading to the failure of radiotherapy [23]. The hampered antitumor immunity in hypoxic tumors is mainly mediated by adenosine receptor signalling, especially $A_{2 A} R$ [24].

Our study confirmed that IR enriched extracellular adenosine, which can thwart the antitumor response [17]. Adenosine is widely involved in intracellular metabolic activities [25]. Radiation induced cell death releases intracellular adenosine into the extracellular environment, and also releases ATP, which can be hydrolyzed into adenosine via CD39/CD73 pathway [26]. On the other hand, radiation can activate DNA repair, which is an energy-consuming process and finally promote ATP consumption and increase adenosine production [22, 27]. Therefore, the enriched adenosine level might result from three aspects: i) direct release of intracellular adenosine, ii) activation of DNA repair and iii) hydrolysis of tumor cell-released ATP via the CD39/CD73 pathway.

The immunosuppressive effect of adenosine has been described $[17,28,29]$. In addition, $\mathrm{A} 2{ }_{\mathrm{A}} \mathrm{R}$ plays a crucial role in the attenuation of immune function [30]. The accumulated extracellular adenosine in the TME can stimulate $A_{2 A}$ and $A_{2 B}$ receptors, and inhibit $\mathrm{T}$ and natural killer (NK) cell function as well as macrophage activation [31-34]. In addition, activation of $\mathrm{A}_{2 \mathrm{~A}} \mathrm{R}$ can promote the differentiation and proliferation of tumor-promoting immune cells, including Treg cells and myeloid-derived suppressor cells (MDSCs) [35]. Inhibition of the adenosine signaling pathway impairs the growth and metastasis of solid tumours [13, 36]. It has also been reported that adenosine can upregulate vascular endothelial growth factor expression [37]. Therefore, adenosine can support tumor angiogenesis.

Immune checkpoint inhibitors (ICIs), such as anti-PD-1/PD-L1 antibodies, have shown good synergistic antitumor effects with IR [38, 39]. IR-induced cancer cell death leads to antigen release, which then activates and recruits effector $\mathrm{T}$ cells to the tumor area [40, 41]. However, IR could cause immunosuppressive effect, with the accumulation of Treg cells as well as the release of immunosuppressive molecules, such as TGF- $\beta$ [42]. Upregulation of immune checkpoint molecule expression in irradiated tumor cells is another major mechanism of IR-induced immunosuppression. Combined IR and immune checkpoint inhibition has produced promising results in clinical trials $[38,39]$. Our study is the first to demonstrate synergistic antitumor effect produced by IR and $A_{2 A} R$ inhibitor. Our results proved that $A_{2 A} R$ antagonist DZD2269 can inhibit CREB phosphorylation induced by adenosine in vivo and in vitro. We also showed the antitumor effect of DZD2269 on colon and breast cancer in murine models. $\mathrm{A}_{2 \mathrm{~A}} \mathrm{R}$ antagonism can protect immune cells from the immunosuppressive effect caused by pre-existing extracellular adenosine accumulation as well as IR-induced adenosine release in the TME. Further studies are necessary to screen novel compounds of $\mathrm{A}_{2 \mathrm{~A}} \mathrm{R}$ antagonist with better antitumor effects and less side effects from natural products [43,44]

Both effector T cells and Treg cells were recruited 7 days after IR. DZD2269 showed radiosensitive effect that reduced Treg cell infiltration and activated effector $\mathrm{T}$ cell function. However, for highly radiosensitive MC38 tumor model, we chose a moderate dose of IR, which was below the reported optimal immune excitation dose (8-12 Gy) [45], The maximum immunostimulatory effect of IR may not have been produced in this situation. DZD2269 may produce a better synergistic antitumor effect with fractionated radiotherapy or stereotactic body radiotherapy (SBRT) than with single-dose radiotherapy in prospective clinical trials.

In summary, our study showed that DZD2269 is a potent and selective $A_{2 A} R$ antagonist with antitumor effect on murine models. $A_{2 A} R$ antagonists can be a novel immunotherapeutic strategy in combination with IR to inhibit IR-induced recruitment of Treg cells and activate $\mathrm{T}$ cell function through enhancing the expression of IFN- $\gamma$. Clinical trials are needed to explore the efficacy and toxicity of combined treatment with IR and $A_{2 A} R$ antagonist.

\section{Abbreviations}

$\mathrm{A}_{2 \mathrm{~A}} \mathrm{R}$ : adenosine $2 \mathrm{~A}$ receptors; CREB: cAMP response element-binding protein; IR: irradiation; Treg cells: regulatory $\mathrm{T}$ cells; TME: tumour microenvironment; NIH: National Cancer Institutes of Health; ATCC: American Type Culture Collection; 5-ITU: 5-iodotubericidin; IACUC: Institutional Animal Care and Use Committee; HPLC: highperformance liquid chromatography; MFI: mean fluorescence intensity; TBST: Tris buffered saline with Tween-20; NECA: 5'-N-ethylcarboxamidoadenosine; pCREB: phosphorylated CREB; NK cells: natural killer cells; MDSCs: myeloid-derived suppressor cells; VEGF: vascular endothelial growth factor; SBRT: stereotactic body radiotherapy.

\section{Supplementary Material}

Supplementary figures.

http://www.jcancer.org/v11p3685s1.pdf 


\section{Acknowledgements}

We gratefully acknowledge Qiuli Guo, Xin Zhang and Yingchun Wang for their invaluable technical assistance.

\section{Funding}

This work was supported by grants from the Subject Assignment of China National Key Research and Development Programme (No. 2018YFC1313201).

\section{Author Contributions}

LGX and JMY conceived and designed the study. $\mathrm{JQH}$ performed the experiments and statistical analysis and wrote the manuscript. DZ, YB, and PY cooperated. All authors read and approved the final manuscript.

\section{Ethical approval}

All applicable international, national, and/or institutional guidelines for the care and use of animals were followed.

\section{Competing Interests}

The authors have declared that no competing interest exists.

\section{References}

1. Smyth MJ, Ngiow SF, Ribas A, Teng MW. Combination cancer immunotherapies tailored to the tumour microenvironment. Nature reviews Clinical oncology. 2016; 13: 143-58.

2. Yao S, Zhu Y, Chen L. Advances in targeting cell surface signalling molecules for immune modulation. Nature reviews Drug discovery. 2013; 12: 130-46.

3. Topalian SL, Hodi FS, Brahmer JR, Gettinger SN, Smith DC, McDermott DF, et al. Safety, activity, and immune correlates of anti-PD-1 antibody in cancer. The New England journal of medicine. 2012; 366: 2443-54

4. Hodi FS, O'Day SJ, McDermott DF, Weber RW, Sosman JA, Haanen JB, et al. Improved survival with ipilimumab in patients with metastatic melanoma. The New England journal of medicine. 2010; 363: 711-23.

5. Leone RD, Lo YC, Powell JD. A2aR antagonists: Next generation checkpoint blockade for cancer immunotherapy. Computational and structural biotechnology journal. 2015; 13: 265-72.

6. Beavis PA, Henderson MA, Giuffrida L, Mills JK, Sek K, Cross RS, et al. Targeting the adenosine $2 \mathrm{~A}$ receptor enhances chimeric antigen receptor $\mathrm{T}$ cell efficacy. The Journal of clinical investigation. 2017; 127: 929-41.

7. Loi S, Pommey S, Haibe-Kains B, Beavis PA, Darcy PK, Smyth MJ, et al. CD73 promotes anthracycline resistance and poor prognosis in triple negative breast cancer. Proceedings of the National Academy of Sciences of the United States of America. 2013; 110: 11091-6.

8. Hosek B, Bohacek J, Sikulova J, Pospisil M, Vacek A. Protection of early cellular damage in 1 Gy-irradiated mice by the elevation of extracellular adenosine. Radiation and environmental biophysics. 1992; 31: 289-97.

9. Clayton A, Al-Taei S, Webber J, Mason MD, Tabi Z. Cancer exosomes express CD39 and CD73, which suppress T cells through adenosine production. Journal of immunology. 2011; 187: 676-83.

10. Hasko G, Pacher P. Regulation of macrophage function by adenosine. Arteriosclerosis, thrombosis, and vascular biology. 2012; 32: 865-9.

11. Bshesh K, Zhao B, Spight D, Biaggioni I, Feokistov I, Denenberg A, et al. The A2A receptor mediates an endogenous regulatory pathway of cytokine expression in THP-1 cells. Journal of leukocyte biology. 2002; 72: 1027-36.

12. de Lera Ruiz M, Lim YH, Zheng J. Adenosine A2A receptor as a drug discovery target. Journal of medicinal chemistry. 2014; 57: 3623-50.

13. Beavis PA, Divisekera U, Paget C, Chow MT, John LB, Devaud C, et al Blockade of A2A receptors potently suppresses the metastasis of CD73+ tumors. Proceedings of the National Academy of Sciences of the United States of America. 2013; 110: 14711-6.

14. Young A, Ngiow SF, Barkauskas DS, Sult E, Hay C, Blake SJ, et al. Co-inhibition of CD73 and A2AR Adenosine Signaling Improves Anti-tumor Immune Responses. Cancer cell. 2016; 30: 391-403.
15. Yamada T, Ohyama H. Radiation-induced interphase death of rat thymocytes is internally programmed (apoptosis). Int J Radiat Biol Relat Stud Phys Chem Med. 1988; 53: 65-75.

16. Willingham SB, Ho PY, Hotson A, Hill C, Piccione EC, Hsieh J, et al. A2AR Antagonism with CPI-444 Induces Antitumor Responses and Augments Efficacy to Anti-PD-(L)1 and Anti-CTLA-4 in Preclinical Models. Cancer immunology research. 2018; 6: 1136-49.

17. Vaupel P, Multhoff G. Adenosine can thwart antitumor immune responses elicited by radiotherapy: Therapeutic strategies alleviating protumor ADO activities. Strahlentherapie und Onkologie: Organ der Deutschen Rontgengesellschaft [et al]. 2016; 192: 279-87.

18. Reits EA, Hodge JW, Herberts CA, Groothuis TA, Chakraborty M, Wansley EK, et al. Radiation modulates the peptide repertoire, enhances MHC class I expression, and induces successful antitumor immunotherapy. The Journal of experimental medicine. 2006; 203: 1259-71.

19. Matsumura S, Wang B, Kawashima N, Braunstein S, Badura M, Cameron TO, et al. Radiation-induced CXCL16 release by breast cancer cells attracts effector T cells. Journal of immunology. 2008; 181: 3099-107.

20. Herbst RS, Soria JC, Kowanetz M, Fine GD, Hamid O, Gordon MS, et al. Predictive correlates of response to the anti-PD-L1 antibody MPDL3280A in cancer patients. Nature. 2014; 515: 563-7.

21. Hanahan D, Weinberg RA. Hallmarks of cancer: the next generation. Cell. 2011; 144: 646-74.

22. Li L, Hu X, Eid JE, Rosenberg AE, Wilky BA, Ban Y, et al. Mutant IDH1 Depletion Downregulates Integrins and Impairs Chondrosarcoma Growth. Cancers (Basel). 2020; 12

23. Eckert F, Zwirner K, Boeke S, Thorwarth D, Zips D, Huber SM. Rationale for Combining Radiotherapy and Immune Checkpoint Inhibition for Patients With Hypoxic Tumors. Frontiers in immunology. 2019; 10: 407.

24. Sitkovsky M, Ohta A. Targeting the hypoxia-adenosinergic signaling pathway to improve the adoptive immunotherapy of cancer. Journal of molecular medicine. 2013; 91: 147-55.

25. Ohta A. A Metabolic Immune Checkpoint: Adenosine in Tumor Microenvironment. Frontiers in immunology. 2016; 7: 109

26. Martins I, Tesniere A, Kepp O, Michaud M, Schlemmer F, Senovilla L, et al. Chemotherapy induces ATP release from tumor cells. Cell cycle. 2009; 8: 3723-8.

27. Biau J, Chautard E, Verrelle P, Dutreix M. Altering DNA Repair to Improve Radiation Therapy: Specific and Multiple Pathway Targeting. Frontiers in oncology. 2019; 9: 1009.

28. Ohta A, Gorelik E, Prasad SJ, Ronchese F, Lukashev D, Wong MK, et al. A2A adenosine receptor protects tumors from antitumor T cells. Proceedings of the National Academy of Sciences of the United States of America. 2006; 103: 13132-7.

29. Hoskin DW, Mader JS, Furlong SJ, Conrad DM, Blay J. Inhibition of T cell and natural killer cell function by adenosine and its contribution to immune evasion by tumor cells (Review). International journal of oncology. 2008; 32: 527-35.

30. Ohta A, Sitkovsky M. Role of G-protein-coupled adenosine receptors in downregulation of inflammation and protection from tissue damage. Nature. 2001; 414: 916-20.

31. Cekic C, Day YJ, Sag D, Linden J. Myeloid expression of adenosine A2A receptor suppresses $\mathrm{T}$ and $\mathrm{NK}$ cell responses in the solid tumor microenvironment. Cancer research. 2014; 74: 7250-9.

32. Raskovalova $\mathrm{T}$, Lokshin A, Huang $\mathrm{X}$, Jackson EK, Gorelik E. Adenosine-mediated inhibition of cytotoxic activity and cytokine production by IL-2/NKp46-activated NK cells: involvement of protein kinase A isozyme I (PKA I). Immunologic research. 2006; 36: 91-9.

33. Kjaergaard J, Hatfield S, Jones G, Ohta A, Sitkovsky M. A2A Adenosine Receptor Gene Deletion or Synthetic A2A Antagonist Liberate Tumor-Reactive CD8(+) T Cells from Tumor-Induced Immunosuppression. Journal of immunology. 2018; 201: 782-91.

34. Csoka B, Selmeczy Z, Koscso B, Nemeth ZH, Pacher P, Murray PJ, et al. Adenosine promotes alternative macrophage activation via $\mathrm{A} 2 \mathrm{~A}$ and $\mathrm{A} 2 \mathrm{~B}$ receptors. FASEB journal : official publication of the Federation of American Societies for Experimental Biology. 2012; 26: 376-86.

35. Ryzhov S, Novitskiy SV, Goldstein AE, Biktasova A, Blackburn MR, Biaggioni $\mathrm{I}$, et al. Adenosinergic regulation of the expansion and immunosuppressive activity of CD11b+Gr1+ cells. Journal of immunology. 2011; 187: 6120-9.

36. Stagg J, Divisekera U, McLaughlin N, Sharkey J, Pommey S, Denoyer D, et al. Anti-CD73 antibody therapy inhibits breast tumor growth and metastasis. Proceedings of the National Academy of Sciences of the United States of America. 2010; 107: 1547-52.

37. Ernens I, Leonard F, Vausort M, Rolland-Turner M, Devaux Y, Wagner DR. Adenosine up-regulates vascular endothelial growth factor in human macrophages. Biochemical and biophysical research communications. 2010; 392: 351-6

38. Shaverdian N, Lisberg AE, Bornazyan K, Veruttipong D, Goldman JW, Formenti SC, et al. Previous radiotherapy and the clinical activity and toxicity of pembrolizumab in the treatment of non-small-cell lung cancer: a secondary analysis of the KEYNOTE-001 phase 1 trial. The Lancet Oncology. 2017; 18: 895-903.

39. Antonia SJ, Villegas A, Daniel D, Vicente D, Murakami S, Hui R, et al. Durvalumab after Chemoradiotherapy in Stage III Non-Small-Cell Lung Cancer. The New England journal of medicine. 2017; 377: 1919-29. 
40. Dovedi SJ, Cheadle EJ, Popple AL, Poon E, Morrow M, Stewart R, et al. Fractionated Radiation Therapy Stimulates Antitumor Immunity Mediated by Both Resident and Infiltrating Polyclonal T-cell Populations when Combined with PD-1 Blockade. Clinical cancer research : an official journal of the American Association for Cancer Research. 2017; 23: 5514-26.

41. Lugade AA, Moran JP, Gerber SA, Rose RC, Frelinger JG, Lord EM. Local radiation therapy of B16 melanoma tumors increases the generation of tumor antigen-specific effector cells that traffic to the tumor. Journal of immunology. 2005; 174: 7516-23.

42. Persa E, Balogh A, Safrany G, Lumniczky K. The effect of ionizing radiation on regulatory T cells in health and disease. Cancer letters. 2015; 368: 252-61.

43. Montes FQ, Vázquez-Hernández A, Fenton-Navarro B. Active compounds of medicinal plants, mechanism for antioxidant and beneficial effects. Phyton, International Journal of Experimental Botany 2019;88:1-10.

44. Villa-Hernández JM, García-Ocón B, Sierra-Palacios EC, Pelayo-Zaldivar C. Molecular biology techniques as new alternatives for medicinal plant identification. Phyton, Int J Exp Botany 2018;87: 72-78.

45. Vanpouille-Box C, Alard A, Aryankalayil MJ, Sarfraz Y, Diamond JM, Schneider RJ, et al. DNA exonuclease Trex1 regulates radiotherapy-induced tumour immunogenicity. Nature communications. 2017; 8: 15618. 